\title{
Influence of age on bupivacaine cardiac arrhythmogenic effects
}

\author{
Marcio G. Kiuchi ${ }^{1 *}$, Gisele Zapata-Sudo², Margarete M. Trachez ${ }^{3}$ and Roberto T. Sudo ${ }^{2}$ \\ ${ }^{1}$ Artificial Cardiac Stimulation and Cardiac Surgery Division, Department of Medicine, Universidade Federal Fluminense, Niterói, RJ, Brazil \\ ${ }^{2}$ Programa de Desenvolvimento de Farmacos, Instituto de Ciências Biomédicas, Universidade Federal do Rio de Janeiro, Rio de Janeiro, Brazil \\ ${ }^{3}$ Serviço de Anestesiologia, Departamento de Cirurgia, Universidade Federal Fluminense, Niterói, RJ, Brazil
}

\begin{abstract}
The cardiotoxic effects of bupivacaine, a widely used local anesthetic, may be age-dependent because neonates and children tolerate a higher plasma concentration of bupivacaine after intravenous administration than adults. No studies have compared the toxicity profiles of the bupivacaine isomers in human neonates and children, but differences in the lethal dose have been observed between adult and younger rats. Here, we determined the age dependency of cardiac toxicity induced by racemic $\mathrm{RS}( \pm)$ bupivacaine and its levo $\mathrm{S}(-)$ isomer in hearts obtained from 2- and 16-week-old male Wistar rats ( $\mathrm{n}=30$ each) using a Langendorff ex vivo assay. We found that both $\mathrm{RS}( \pm)$ and $\mathrm{S}(-)$ bupivacaine significantly reduced heart rate and prolonged the PR interval and QRS complex duration. The effects of both compounds were significantly greater in older rats, and $\mathrm{RS}( \pm)$ bupivacaine had a greater effect than $\mathrm{S}(-)$ bupivacaine. Furthermore, RS( \pm ) bupivacaine induced significantly more severe arrhythmias in 16-week-old than in 2-week-old rats. By contrast, the same concentration of $\mathrm{S}(-)$ bupivacaine was associated with mild arrhythmias in both age groups. Thus, although $\mathrm{RS}( \pm)$ bupivacaine induced greater cardiotoxicity than $\mathrm{S}(-)$ bupivacaine, the effects of both compounds were age related, with hearts from older animals showing more signs of toxicity.
\end{abstract}

\section{Introduction}

Previous studies have shown that accidental intravenous (IV) administration of bupivacaine leads to plasma concentrations from 0.5 till $5 \mu \mathrm{g} \bullet \mathrm{mL}^{-1}(1.7-17 \mu \mathrm{M})$, which depresses myocardial conduction and causes caridotoxicity [1-3]. Racemic RS( \pm ) bupivacaine is the most widely used local anesthetic because of its longer effectiveness than lidocaine $[4,5]$ and selective action on different neuronal fibers. However, RS $( \pm)$ bupivacaine is 6- to 10 -fold more cardiotoxic than lidocaine [6-8], and dextro $\mathrm{R}(+)$ bupivacaine is associated with greater negative chronotropism and more cardiac arrhythmias than the levo $\mathrm{S}(-)$ isomer [9-11]. This cardiotoxic consequence has been explored in pediatric patients for several decades with controversial results. The results of some studies have suggested that neonates and children may support higher blood levels of bupivacaine after IV administration than adults $[12,13]$, but other studies have demonstrated an increased fetal [14] and neonatal heart susceptibility to $\mathrm{RS}( \pm)$ bupivacaine $[15,16]$.

Our group previously reported a significant difference in lethal dose in younger animals ( 2 weeks) compared with that in older animals (>4 weeks) for both RS $( \pm$ ) and S(-) bupivacaine [17]. Two weeks of age appeared to be the limit for decreased susceptibility to the toxic effects of bupivacaine because no difference in lethal dose was detected in animals elder than four weeks. On the other hand, dissimilarities in susceptibility to the drugs were detected in the younger group. The lethal dose in 2-week-old animals was approximately 4 -fold higher for S(-) bupivacaine and approximately 2 -fold higher for $\mathrm{RS}( \pm)$ bupivacaine than that in older animals. This is in agreement with reports that human neonates and children support a higher plasma concentration of bupivacaine after accidental IV administration [12,13]. No data have been reported comparing toxicity profiles between the bupivacaine isomers in human neonates or children.
In the present study, we investigated the age dependency of the cardiac toxicity induced by $\mathrm{RS}( \pm)$ bupivacaine and its $\mathrm{S}(-)$ isomer. Specifically, our aims were to find possible age-related differences induced by the presence of $\mathrm{RS}( \pm)$ or $\mathrm{S}(-)$ bupivacaine in heart rate (HR), PR interval, and QRS complex duration as well in the induction and reversion of cardiac arrhythmias using hearts obtained from younger ( 2 weeks) and older animals (16 weeks).

\section{Methods}

\section{Compliance with ethical standards}

All the protocols used in this work was approved by the Universidade Federal do Rio de Janeiro Animal Care and Use Committee. Animals were accommodated in a temperature, humidity, and 12-h light/dark controlled room. The animals had access to water and food ad libitum. All exertions were made to minimize the suffering and numbers of animals used in this study.

\section{Retrograde cardiac perfusion}

Male Wistar rats $2(n=30)$ and $16(n=30)$ weeks of age were humanely killed using an anesthetic overdose (pentobarbital, $50 \mathrm{mg} /$ $\mathrm{kg}$ ) in accordance with procedures outlined in Schedule 1 of the UK

Correspondence to: Márcio Galindo Kiuchi, Universidade Federal Fluminense, Rua Murilo Portugal 35/503 Niterói, RJ, Brazil, Tel: 24360-410; E-mail: marciokiuchi@gmail.com

Key words: cardiac arrhythmias, $R S( \pm)$ bupivacaine, $S(-)$ bupivacaine, chronotropic effect, age dependence, Langendorff

Received: December 26, 2016; Accepted: January 17, 2017; Published: January 20,2017 
Home Office Animals (Scientific Procedures) Act 1986.

Hearts were quickly excised, retrogradely perfused through the aorta for $5 \mathrm{~min}$ at $10 \mathrm{~mL} \cdot \mathrm{min}^{-1}$, and submersed into a chamber filled with oxygenated Tyrode's solution (containing in mmol/L: 123 $\mathrm{NaCl}, 1.8 \mathrm{CaCl}_{2}, 5.4 \mathrm{KCl}, 1.2 \mathrm{MgCl}_{2}, 1.4 \mathrm{NaH}_{2} \mathrm{PO}_{4}, 24 \mathrm{NaHCO}_{3}$, and 10 glucose; bubbled with $95 \% \mathrm{O}_{2}-5 \% \mathrm{CO}_{2}$; $\mathrm{pH} 7.4$ at $35 \pm 2{ }^{\circ} \mathrm{C}$ ) for the Langendorff preparation. For electromechanical uncoupling, blebbistatin ( $10 \mu \mathrm{mol} / \mathrm{L}$; Ascent Scientific, Cambridge, UK) was added after dye loading and before slicing/optical mapping. All compounds were acquired from Sigma-Aldrich (Dorset, UK) unless otherwise stated. After $30 \mathrm{~min}$, electrocardiogram (EKG) recordings were obtained through three glass pipette electrodes filled with $1 \mathrm{M} \mathrm{KCl}$ solution positioned in the chamber, and the whole heart was exposed to incrementally increasing concentrations $(0.1-10 \mu \mathrm{M})$ of $\mathrm{RS}( \pm)$ bupivacaine or $\mathrm{S}(-)$ bupivacaine added to the solution for a duration of $5 \mathrm{~min}$ each. This local anesthetic concentration range was based on that used in a previous experiment performed with an isolated heart [18]. The EKG was recorded on a polygraph (Gould Polygraph Brush 2400; Gould Inc., Valley View, OH) previously (control) and 5 min after the adding of each concentration of RS( \pm ) bupivacaine or $\mathrm{S}(-)$ bupivacaine and $30 \mathrm{~min}$ after washout.

\section{Statistical analysis}

Data are presented as a percentage of control parameters (HR, PR interval, and QRS complex duration) measured at the start of each experiment because the baseline data from animals of different ages were heterogeneous. Data are expressed as the mean \pm SEM. Intergroup comparisons were performed using one-way analysis of variance (ANOVA) with Bonferroni multiple comparison tests (comparing selected pairs). The intragroup comparisons were performed using repeated measures one-way ANOVA with Bonferroni multiple comparison tests (comparing selected pairs). Differences in frequency were compared with the chi-square test. $\mathrm{P}$ values $<0.05$ are considered significant. All statistical analysis was executed using GraphPad Prism version 7.0 software (GraphPad Software, La Jolla, CA, USA).

\section{Results}

\section{Heart rate}

In 16-week-old rats, HR decreased in the presence of RS( \pm ) bupivacaine $(\mathrm{n}=15)$ from $100 \%$ to $93.2 \pm 1.0 \%, 89.8 \pm 1.1 \%, 87.8 \pm$ $3.1 \%, 84.3 \pm 3.2 \%, 72.2 \pm 3.5 \%$, and $63.8 \pm 3.9 \%$ at concentrations of $0.1,0.5,1.0,2.5,5.0$, and $10.0 \mu \mathrm{M}$, respectively $(\mathrm{P}>0.05$ at $0.1 \mu \mathrm{M}$, all others $\mathrm{P}<0.05$, compared with baseline), and in the presence of $\mathrm{S}(-)$ bupivacaine $(\mathrm{n}=15)$ to $99.6 \pm 1.8 \%, 94.5 \pm 2.3 \%, 95.1 \pm 2.5 \%, 92.4$ $\pm 1.4 \%, 84.7 \pm 1.8 \%$, and $81.0 \pm 3.6 \%$, respectively $(\mathrm{P}>0.05$ until 2.5 $\mu \mathrm{M}$, all others $\mathrm{P}<0.05$, compared with baseline). The differences in the effects of RS( \pm )and $\mathrm{S}(-)$ bupivacaine were statistically significant at concentrations of 5.0 and $10.0 \mu \mathrm{M}(\mathrm{P}<0.05$ for both comparisons of the same concentrations; Figure 1).

In 2-week-old rats, HR also decreased in the presence of RS( \pm ) bupivacaine ( $\mathrm{n}=15)$ from $100 \%$ to $98.2 \pm 0.6 \%, 96.3 \pm 1.9 \%, 84.6 \pm 4.4 \%$, $86.4 \pm 3.9 \%, 80.92 \pm 3.3 \%$, and $73.7 \pm 4.6 \%$, at concentrations of $0.1,0.5$, $1.0,2.5,5.0$, and $10.0 \mu \mathrm{M}$, respectively $(\mathrm{P}>0.05$ for concentrations up to $0.1 \mu \mathrm{M}$, all others $\mathrm{P}<0.05$, compared with baseline), and in the presence of $\mathrm{S}(-)$ bupivacaine $(\mathrm{n}=15)$ to $99.8 \pm 0.8 \%, 98.6 \pm 1.7 \%, 96.6 \pm 3.8 \%$, $95.8 \pm 3.2 \%, 93.3 \pm 1.2 \%$, and $93.1 \pm 2.8 \%$, respectively $(\mathrm{P}>0.05$ for all associations with baseline). The difference in the effects of RS( \pm )and $\mathrm{S}(-)$ bupivacaine were statistically significant at concentrations of 5.0

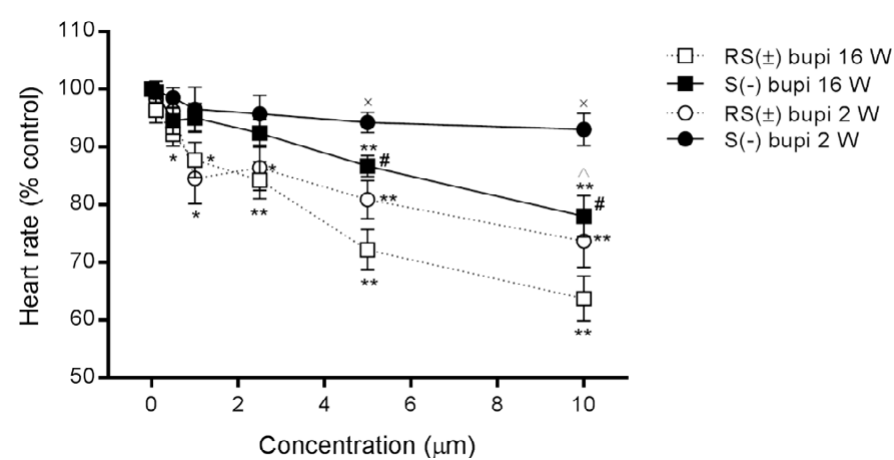

Figure 1. Heart rate in the absence (control) and presence of $\mathrm{RS}( \pm$ ) and $\mathrm{S}(-)$ bupivacaine (bupi) at concentrations of $0.1,0.5,1.0,2.5,5.0$, and $10.0 \mu \mathrm{M}$ in hearts obtained from 2- and 16-week-old rats ( $2 \mathrm{~W}$ and $16 \mathrm{~W}$, respectively) and retrogradely perfused using the Langendorff ex vivo preparation. Values represent the mean \pm SEM $(\mathrm{n}=15$ for each group). ${ }^{*} \mathrm{P}<0.05$ and ${ }^{* *} \mathrm{P}<0.001$ for each concentration $v s$. the respective control. ${ }^{*} \mathrm{P}<0.05$ for $\mathrm{RS}( \pm) v s . \mathrm{S}(-)$ bupivacaine in 16 -week-old rats. ${ }^{\mathrm{x}}<0.05$ for $\mathrm{RS}( \pm) v s . \mathrm{S}(-)$ bupivacaine in 2 -week-old rats. ${ }^{\mathrm{P}}<0.05$ for $16-v s$. 2 -week-old rats in the presence of $\mathrm{S}(-)$ bupivacaine.

and $10.0 \mu \mathrm{M}(\mathrm{P}<0.05$ for both comparisons at the same concentration).

The difference in heart rates between 2- and 16-week-old rats was statistically significant for $\mathrm{S}(-)$ bupivacaine at a concentration of 10.0 $\mu \mathrm{M}(\mathrm{P}<0.05)$, as shown in Figure 1.

\section{PR interval}

In 16-week-old rats, the PR interval was prolonged in the presence of $\mathrm{RS}( \pm)$ bupivacaine $(\mathrm{n}=15)$ from $100 \%$ to $111.0 \pm 5.2 \%, 130.0 \pm$ $2.8 \%, 137.8 \pm 2.9 \%, 140.1 \pm 2.0 \%, 144.8 \pm 3.1 \%$, and $160.4 \pm 2.5 \%$ at concentrations of $0.1,0.5,1.0,2.5,5.0$, and $10.0 \mu \mathrm{M}$, respectively ( $\mathrm{P}>0.05$ at $0.1 \mu \mathrm{M}$, all others $\mathrm{P}<0.05$, compared with baseline), and in the presence of $S(-)$ bupivacaine $(n=15)$ to $102.2 \pm 1.1 \%, 111.4 \pm 2.7 \%$, $113.0 \pm 1.0 \%, 118.7 \pm 1.4 \%, 120.5 \pm 1.1 \%$, and $123.4 \pm 2.6 \%$, respectively ( $\mathrm{P}>0.05$ at $0.1 \mu \mathrm{M}$, all others $\mathrm{P}<0.05$, compared with baseline). Comparisons between $\mathrm{RS}( \pm)$ bupivacaine and $\mathrm{S}(-)$ bupivacaine showed statistically significance at concentrations from 0.5 to $10.0 \mu \mathrm{M}$ $(\mathrm{P}<0.001$, for all comparisons at the same concentration; Figure 2).

In 2-week-old rats, the PR interval was also prolonged in the presence of $\mathrm{RS}( \pm)$ bupivacaine $(\mathrm{n}=15)$ from $100 \%$ to $103.0 \pm 1.0 \%$, $111.0 \pm 3.4 \%, 118.0 \pm 3.8 \%, 121.0 \pm 2.2 \%, 123.0 \pm 2.9 \%$, and 136.0 $\pm 4.0 \%$ at concentrations of $0.1,0.5,1.0,2.5,5.0$, and $10.0 \mu \mathrm{M}$, respectively, $(\mathrm{P}>0.05$ at $0.1 \mu \mathrm{M}$, all others $\mathrm{P}<0.05$, compared with baseline), and in the presence of $S(-)$ bupivacaine $(n=15)$ to 101.0 $\pm 0.8 \%, 102.0 \pm 1.6 \%, 104.0 \pm 2.0 \%, 105.0 \pm 0.8 \%, 107.8 \pm 0.4 \%$, and $109.9 \pm 1.2 \%$, respectively $(\mathrm{P}>0.05$ until $2.5 \mu \mathrm{M}$, all others $\mathrm{P}<0.05$ compared with baseline). The difference in the effects of RS $( \pm)$ and S(-) bupivacaine were statistically significant at concentrations from 1.0 to $10.0 \mu \mathrm{M}(\mathrm{P}<0.001$ for all comparisons at the same concentration). The difference in PR intervals in hearts derived from 2- and 16-week-old rats was statistically significant with perfusions of RS( \pm ) bupivacaine at concentrations from 0.5 to $10.0 \mu \mathrm{M}$ and with $\mathrm{S}(-)$ bupivacaine at concentrations from 2.5 to $10.0 \mu \mathrm{M}(\mathrm{P}<0.001$ for all comparisons at the same dose), as shown in Figure 2.

\section{QRS complex}

In 16-week-old rats, the QRS complex duration was prolonged in the presence of $\mathrm{RS}( \pm)$ bupivacaine $(\mathrm{n}=15)$ from $100 \%$ to $153.0 \pm 2.1 \%$, $177.5 \pm 3.4 \%, 188.2 \pm 2.8 \%, 224.5 \pm 3.6 \%, 260.3 \pm 4.2 \%$, and $298.0 \pm 4.5 \%$ at concentrations of $0.1,0.5,1.0,2.5,5.0$, and $10.0 \mu \mathrm{M}$, respectively, $(\mathrm{P}<0.001$ for all comparisons with baseline $)$, and in the presence of $\mathrm{S}(-)$ 


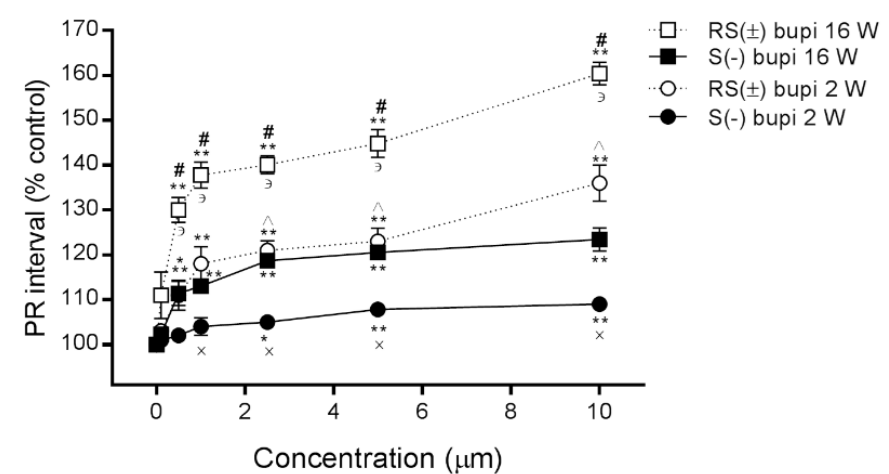

Figure 2. PR interval prolongation in the absence (control) and presence of $\mathrm{RS}( \pm$ ) and $\mathrm{S}(-)$ bupivacaine (bupi) at concentrations of $0.1,0.5,1.0,2.5,5.0$, and $10.0 \mu \mathrm{M}$ on hearts obtained from 2- and 16-week-old rats ( $2 \mathrm{~W}$ and $16 \mathrm{~W}$, respectively) and retrogradely perfused using the Langendorff ex vivo preparation. Values represent mean \pm SEM $(n=15$ for each group). $* \mathrm{P}<0.05$ and ${ }^{* *} \mathrm{P}<0.001$ for each concentration $v s$. the respective control. ${ }^{*} \mathrm{P}<0.001$ for $\mathrm{RS}( \pm)$ vs. $\mathrm{S}(-)$ bupivacaine in 16-week-old rats. ${ }^{x} \mathrm{P}<0.001$ for $\mathrm{RS}( \pm)$ vs. $\mathrm{S}(-)$ bupivacaine in 2-week-old rats. ${ }^{\wedge} \mathrm{P}<0.05$ for 16 - $v$ s. 2 -week-old rats in the presence of $\mathrm{S}(-)$ bupivacaine. ${ }^{3} \mathrm{P}<0.001$ for $16-v$ s. 2 -week-old rats in the presence of $\mathrm{RS}( \pm)$ bupivacaine.

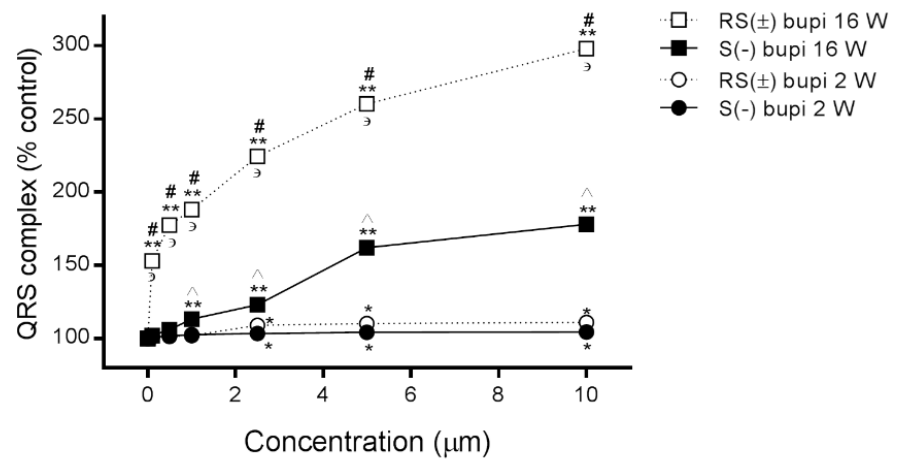

Figure 3. QRS complex duration in the absence (control) and presence of $\mathrm{RS}( \pm)$ and $\mathrm{S}(-)$ bupivacaine (bupi) at concentrations of $0.1,0.5,1.0,2.5,5.0$ and $10.0 \mu \mathrm{M}$ in hearts obtained from 2- and 16-week-old rats ( $2 \mathrm{~W}$ and $16 \mathrm{~W}$, respectively) and retrogradely perfused using the Langendorff ex vivo preparation. Values represent mean $\pm \operatorname{SEM}(\mathrm{n}=15$ for each group). $* \mathrm{P}<0.05$ and ${ }^{* *} \mathrm{P}<0.001$ for each concentration $v s$. the respective control. ${ }^{*} \mathrm{P}<0.001$ for $\mathrm{RS}( \pm)$ vs. $\mathrm{S}(-)$ bupivacaine in 16 -week-old rats. ${ }^{\wedge} \mathrm{P}<0.001$ for $16-v s$. 2 -week-old rats in the presence of $\mathrm{S}(-)$ bupivacaine. ${ }^{3} \mathrm{P}<0.001$ for $16-v s$. 2-week-old rats in the presence of $\mathrm{RS}( \pm)$ bupivacaine.

bupivacaine $(\mathrm{n}=15)$ to $102.0 \pm 0.8 \%, 106.0 \pm 2.0 \%, 113.2 \pm 1.8 \%, 123.0$ $\pm 1.0 \%, 162.0 \pm 2.4 \%$, and $178.0 \pm 3.0 \%$, respectively $(\mathrm{P}>0.05$ for 0.1 and $0.5 \mu \mathrm{M}$, all others $\mathrm{P}<0.05$, compared with baseline). Comparisons between RS $( \pm)$ bupivacaine and $S(-)$ bupivacaine showed statistical significance at all concentrations tested, $(\mathrm{P}<0.001$ for all comparisons at the same concentration).

In 2-week-old rats, the QRS complex duration was also prolonged in the presence of RS $( \pm$ ) bupivacaine $(\mathrm{n}=15)$ from $100 \%$ to $101.0 \pm$ $1.0 \%, 101.4 \pm 1.2 \%, 102.0 \pm 1.3 \%, 109.0 \pm 2.8 \%, 110.2 \pm 2.7 \%$, and $111.0 \pm 3.4 \%$ at concentrations of $0.1,0.5,1.0,2.5,5.0$, and $10.0 \mu \mathrm{M}$, respectively ( $\mathrm{P}>0.05$ for concentrations up to $1 \mu \mathrm{M}$, all others $\mathrm{P}<0.05$ compared with baseline), and in the presence of $\mathrm{S}(-)$ bupivacaine $(\mathrm{n}=15)$ to $101.0 \pm 1.0 \%, 101.8 \pm 1.2 \%, 102.8 \pm 0.5 \%, 103.6 \pm 1.2 \%$, $104.2 \pm 0.5 \%$ and $104.5 \pm 0.7 \%$, respectively ( $\mathrm{P}>0.05$ up to $1 \mu \mathrm{M}$, all others $\mathrm{P}<0.05$, compared with baseline). Comparisons between $\mathrm{RS}( \pm)$ bupivacaine and $\mathrm{S}(-)$ bupivacaine showed no statistical significance at any concentration tested $(\mathrm{P}>0.05$ for all comparisons at the same concentration).

The differences in the QRS complex duration in hearts derived from 2- and 16-week-old rats were statistically significant in the presence of
$\mathrm{RS}( \pm)$ bupivacaine at all concentrations tested and in the presence of $\mathrm{S}(-)$ bupivacaine at concentrations from 1.0 to $10.0 \mu \mathrm{M}(\mathrm{P}<0.001$ for all comparisons of the same drug at the same dose), as shown in Figure 3.

\section{Cardiac arrhythmias}

The effects of RS( \pm ) and $\mathrm{S}(-)$ bupivacaine on the induction and reversion of cardiac arrhythmias in 2 and 16-week-old rats are displayed in Table 1. RS $( \pm)$ bupivacaine $(10 \mu \mathrm{M})$ induced frequent and severe arrhythmias in 16-week-old animals, whereas fewer arrhythmias were observed at the same concentration of $\mathrm{S}(-)$ bupivacaine (Table 2).

\section{Discussion}

In this study, we investigated the age dependency of the cardiac toxicity induced by $\mathrm{RS}( \pm)$ bupivacaine and its $\mathrm{S}(-)$ isomer. A significant age-related difference in the effects of both RS $( \pm)$ and $S(-)$ bupivacaine on HR, PR interval, and QRS complex duration in addition to the induction and reversion of cardiac arrhythmias was observed between younger ( 2 week old) (which is an age approximately similar to 3-yearold humans) and older animals (16 weeks).

The cardiotoxicity of $\mathrm{RS}( \pm)$ bupivacaine and its isomers is attributed to their blocking sodium [19], potassium [20], and L-type calcium channels $[18,21]$ in the sarcolemma of cardiomyocytes. In addition, local anesthetics can either decrease $[22,23]$ or increase $\mathrm{Ca}^{2+}$ mobilization [24] from the sarcoplasmic reticulum and also decrease the sensitivity of myofilaments to $\mathrm{Ca}^{2+}$ [25]. The stereoselective effects induced by the bupivacaine isomers, $\mathrm{R}(+)$ and $\mathrm{S}(-)$, have been intensively studied to determine which causes less cardiotoxicity while still providing potent nerve blockade. Previous laboratory and clinical studies have shown that $\mathrm{R}(+)$ and $\mathrm{S}(-)$ bupivacaine have similar local anesthetic durations [26]; however, $\mathrm{R}(+)$ bupivacaine is associated with a more intense negative chronotropism [19] and a more arrhythmogenic effect than the S(-) isomer [9-11]. In the present study, RS $( \pm)$ bupivacaine, especially at the higher concentrations, significantly lowered HR in 16 and 2-week-old rats, with the effect more prominent in the older animals.

Compared with $\mathrm{S}(-)$ bupivacaine, $\mathrm{RS}( \pm)$ bupivacaine caused a striking effect in both age groups, extending the PR interval approximately $160 \%$ and $136 \%$ in 16- and 2-week-old rats, respectively, at the highest concentration. The effects of both compounds on the PR interval prolongation were more prominent in older rats for most concentrations. This finding for RS $( \pm)$ bupivacaine may be explained, at least in part, by the high number of atrioventricular blocks, from mild to severe, induced in both the younger and older animals. The QRS complex corresponds to the depolarization of the right and left ventricles of the heart. Broadening of the QRS complex reproduces reduced intraventricular conduction velocity, which typically results from altered $\mathrm{Na}^{+}$channel function. As expected, $\mathrm{RS}( \pm)$ and $\mathrm{S}(-)$ bupivacaine caused a marked effect in 16-week-old rats, in comparison to 2-week-old rats, increasing the QRS complex duration approximately $298 \%$ and $178 \%$, respectively, at the highest concentrations, with the effect most exacerbated by RS $( \pm)$ bupivacaine. There was no difference in this effect between these local anesthetics in young rats. These findings may explain the high number of severe ventricular arrhythmias (ventricular tachycardia, ventricular fibrillation, and asystole) observed when the hearts obtained from 16-week-old rats were exposed to RS $( \pm)$ bupivacaine.

Despite numerous studies examining the effect of lipid emulsion on bupivacaine-induced cardiac toxicity, few studies have examined 
Table 1. Effects of RS ( \pm ) and S (-) bupivacaine on cardiac arrhythmia in 2- and 16-week-old rats.

\begin{tabular}{|c|c|c|c|c|c|c|}
\hline \multirow[t]{2}{*}{ Induction/reversion of cardiac arrhythmia } & \multicolumn{6}{|c|}{ Concentrations $(\mu \mathrm{M})$} \\
\hline & 0.1 & 0.5 & 1.0 & 2.5 & 5.0 & 10.0 \\
\hline \multicolumn{7}{|c|}{$\mathrm{S}(-)$ bupivacaine effects in 2-week-old animals $(\mathrm{n}=15)$} \\
\hline Premature atrial contraction & & & & & $1 / 1$ & \\
\hline Premature ventricular contraction & & $2 / 2$ & $3 / 3$ & $4 / 4$ & $3 / 3$ & $2 / 2$ \\
\hline Ventricular fibrillation & & & & $1 / 1$ & $1 / 1$ & $1 / 1$ \\
\hline \multicolumn{7}{|c|}{$\mathrm{RS}( \pm)$ bupivacaine effects in 2-week-old animals $(\mathrm{n}=15)$} \\
\hline Premature atrial contraction & $2 / 2$ & $1 / 1$ & $1 / 1$ & & & \\
\hline Premature ventricular contraction & $4 / 4$ & $1 / 1$ & $2 / 2$ & $2 / 2$ & $2 / 2$ & $2 / 2$ \\
\hline $1^{\text {st }}$ degree atrioventricular block & $1 / 1$ & $2 / 1$ & $3 / 1$ & $4 / 1$ & $3 / 1$ & $1 / 1$ \\
\hline $2^{\text {nd }}$ degree atrioventricular block & $2 / 2$ & $3 / 2$ & $2 / 2$ & $2 / 1$ & $2 / 1$ & $1 / 1$ \\
\hline $3^{\text {rd }}$ degree atrioventricular block & & & & & $1 / 1$ & $3 / 3$ \\
\hline Atrial fibrillation & & & $1 / 1$ & $1 / 1$ & $1 / 1$ & $2 / 2$ \\
\hline Ventricular fibrillation & $1 / 1$ & $1 / 1$ & $1 / 1$ & $1 / 1$ & $1 / 1$ & $2 / 2$ \\
\hline \multicolumn{7}{|c|}{$\mathrm{S}(-)$ bupivacaine effects in 16-week-old animals $(\mathrm{n}=15)$} \\
\hline Premature atrial contraction & $5 / 1$ & $8 / 3$ & $6 / 1$ & $10 / 3$ & $7 / 1$ & $7 / 2$ \\
\hline Premature ventricular contraction & & $1 / 1$ & $1 / 1$ & $1 / 1$ & $1 / 1$ & $3 / 3$ \\
\hline $1^{\text {st }}$ degree atrioventricular block & & & $1 / 1$ & $1 / 1$ & $1 / 1$ & $2 / 2$ \\
\hline Atrial fibrillation & & & $1 / 1$ & & $1 / 1$ & \\
\hline Ventricular fibrillation & & & $1 / 0$ & & & \\
\hline \multicolumn{7}{|c|}{$\mathrm{RS}( \pm)$ bupivacaine effects in 16 -week-old animals $(\mathrm{n}=15)$} \\
\hline Premature atrial contraction & $1 / 1$ & $1 / 1$ & & $2 / 2$ & $2 / 2$ & $1 / 1$ \\
\hline Premature ventricular contraction & $2 / 2$ & $4 / 3$ & $5 / 3$ & $3 / 1$ & $4 / 2$ & $5 / 4$ \\
\hline $1^{\text {st }}$ degree atrioventricular block & $2 / 1$ & $1 / 0$ & & $3 / 0$ & $3 / 0$ & \\
\hline $2^{\text {nd }}$ degree atrioventricular block & $2 / 1$ & $2 / 1$ & $2 / 1$ & & & $1 / 0$ \\
\hline $3^{\text {rd }}$ degree atrioventricular block & $2 / 0$ & $2 / 0$ & $2 / 0$ & $4 / 1$ & $3 / 1$ & $6 / 6$ \\
\hline Atrial tachycardia & & & & & & $1 / 1$ \\
\hline Atrial fibrillation & & $1 / 0$ & $1 / 0$ & $1 / 0$ & $3 / 2$ & $2 / 2$ \\
\hline Ventricular tachycardia & & $1 / 1$ & $1 / 0$ & & & $3 / 0$ \\
\hline Ventricular fibrillation & & $1 / 1$ & $2 / 2$ & $2 / 2$ & & $6 / 1$ \\
\hline Junctional rhythm & & & & & $1 / 1$ & $2 / 1$ \\
\hline Asystole & & & & & $2 / 2$ & $6 / 6$ \\
\hline
\end{tabular}

Effects of various concentrations of $\mathrm{RS}( \pm)$ and $\mathrm{S}(-)$ bupivacaine on theinduction and reversion of cardiac arrhythmias in isolated perfused hearts obtained from rats of two ages

Table 2. Effects of RS( \pm ) orS(-) bupivacaine $(10 \mu \mathrm{M})$ on severe cardiac arrhythmias.

\begin{tabular}{|l|c|c|c|c|}
\hline \multirow{2}{*}{ Types of arrhythmia } & \multicolumn{2}{|c|}{ RS $( \pm)$ bupivacaine } & \multicolumn{2}{|c|}{ P $(-)$ bupivacaine } \\
\cline { 2 - 5 } & 2 weeks & $\mathbf{1 6}$ weeks & 2 weeks & $\mathbf{1 6}$ weeks \\
\hline $3^{\text {rd }}$ degree atrioventricular block & 3 & 6 & 0 \\
\hline Ventricular tachycardia & 0 & 2 & 0 & 0 \\
\hline Ventricular fibrillation & 2 & 6 & 0 \\
\hline Asystole & 0 & 6 & 0 & 0 \\
\hline
\end{tabular}

Ata concentration of $10 \mu \mathrm{M}, \mathrm{RS}( \pm)$ bupivacaine provoked more frequent and severe arrhythmias thanS (-) bupivacaine did at the same concentration in 16 -week-old rats. For each group, $\mathrm{n}=15$

its effect on local anesthetic-induced central nervous system (CNS) toxicity. One study has shown that lipid emulsion combined with $\mathrm{RS}( \pm)$ or S(-) bupivacaine decreases both CNS and cardiac toxicity [27]. The exposure to bupivacaine $\left(10^{-6} \mathrm{M}, 10^{-5} \mathrm{M}\right.$, and $\left.5.10^{-5} \mathrm{M}\right)$ alone or in the presence of a long-chain triglyceride lipid emulsion $(0.5 \%)$ occasioned in a significant diminution in action potential duration measured at $50 \%$ and $90 \%$ repolarization $(\mathrm{P}<0.01 v$ s. control group). Long-chain triglyceride lipid emulsion inhibits the Purkinje fiber conduction blocks induced by bupivacaine. Moreover, long-chain triglyceride lipid emulsion of $0.5 \%$ attenuates the decrease in Vmax induced by bupivacaine $\left(10^{-6} \mathrm{M}\right.$ and $\left.10^{-5} \mathrm{M}\right)$ [28]. Thus, lipid emulsion has been a key player in the resuscitation from bupivacaine-induced cardiotoxicity [29].

The cardiac changes in the electrical properties induced by local anesthetics might be linked to the variations in the regulation of intracellular $\mathrm{Ca}^{2+}$ concentration that progressively changes with age. In adults, the $\mathrm{Ca}^{2+}$ source required for myofibril activation and cardiac contraction hang on a $\mathrm{Ca}^{2+}$-induced-Ca ${ }^{2+}$-release (CICR) route that is prompted by a small amount of $\mathrm{Ca}^{2+}$ entry into the cell via an L-type $\mathrm{Ca}^{2+}$ channel. In newborns, CICR is not as efficient, likely because of the immaturity of the transverse tubule [30], a lower density of RyR2 [31], and decreased SERCA2 activity [32]. The main sources responsible for cardiac contraction in newborns are the $\mathrm{Ca}^{2+}$ influx via the L-type $\mathrm{Ca}^{2+}$ channel [33-36] and the $\mathrm{Na}^{+} / \mathrm{Ca}^{2+}$ exchanger, which is reversely activated by a decreased intracellular $\mathrm{Na}^{+}$concentration [32]. There is no data regarding the effects of bupivacaine and its $\mathrm{S}(-)$ isomer on the L-type $\mathrm{Ca}^{2+}$ channel nor in the $\mathrm{Na}^{+} / \mathrm{Ca}^{2+}$ exchanger in neonatal rats. The negative chronotropic effect observed with $\mathrm{RS}( \pm)$ bupivacaine may be explicated by a reduction in $\mathrm{Ca}^{2+}$ influx into the cell, triggered by direct interaction with L-type $\mathrm{Ca}^{2+}$ channels on phases 4 and 0 of the sinus node action potential $[18,21]$. Thus, we suggest that RS $( \pm)$ and $\mathrm{S}(-)$ bupivacaine promote a more significant cardiodepressant 
influence in elder animals since the intracellular $\mathrm{Ca}^{2+}$ concentration depends totally on the activation of L-type $\mathrm{Ca}^{2+}$ channels, and these local anesthetics produce a nonstereoselective blockade [18]. As a consequence, the CICR from intracellular stores may be impaired in these older animals. Previous studies have demonstrated that the diastolic $\mathrm{Ca}^{2+}$ concentration in spontaneously activated intact myocytes increased 15 -fold in the presence of $\mathrm{RS}( \pm), \mathrm{R}(+)$, and $\mathrm{S}(-)$ bupivacaine. These data suggest that bupivacaine may impair the mechanisms for removal of $\mathrm{Ca}^{2+}$ from the cytoplasm, such as via SERCA2, the $\mathrm{Na}^{+} /$ $\mathrm{Ca}^{2+}$ exchanger, or the ATP-dependent $\mathrm{Ca}^{2+}$ pump, which are located in the sarcolemma [37]. Furthermore, the $\mathrm{Ca}^{2+}$ threshold for activation of myofibrils is reduced by $\mathrm{RS}( \pm)$ and $\mathrm{S}(-)$ bupivacaine, but this effect is not age dependent [17]. This set of events may have led to higher $\mathrm{Ca}^{2+}$ concentrations inside the cell, inducing the extended PR interval and QRS complex duration, which contributed to the genesis of the arrhythmias observed in the present study.

\section{Study limitations}

The first limitation in extrapolating the interpretation of our results is that this study used an animal model. Furthermore, this was an ex vivo model, which may potentially show differences from in vivo pharmacokinetics. Finally, future studies should endeavor to use a larger sample size.

\section{Conclusions}

In conclusion, compared with the $\mathrm{S}(-)$ isomer, racemic $\mathrm{RS}( \pm)$ bupivacaine induced a greater negative chronotropic effect, prolonged the PR interval, increased the QRS complex duration, and generated more frequent and severe arrhythmias in older than in younger rats.

\section{Disclosures}

None declared.

\section{Acknowledgments}

The authors are thankful to Cristália Produtos Químicos e Farmacêuticos Ltda, São Paulo, Brazil, for supplying the RS( \pm ) and $\mathrm{S}(-)$ bupivacaine.

\section{Funding}

This study was supported by Coordenação de Aperfeiçoamento de Pessoal de Nível Superior (CAPES, Brazil), Conselho Nacional de Desenvolvimento Cientifico e Tecnológico (CNPq, Brazil), Fundação Carlos Chagas Filho de Amparo à Pesquisa do Estado do Rio de Janeiro (FAPERJ, Brazil), and Fundação Universitária Jose Bonifácio (FUJB, Brazil).

\section{Conflict of interest}

GZS and RTS have received financial support (fellowships) from CNPq.

\section{References}

1. Clarkson CW, Hondeghem LM (1985) Mechanism for bupivacaine depression of cardiac conduction: fast block of sodium channels during the action potential with slow recovery from block during diastole. Anesthesiology 62: 396-405. [Crossref]

2. Kotelko DM, Shnider SM, Dailey PA, Brizgys RV, Levinson G, et al. (1984) Bupivacaine-induced cardiac arrhythmias in sheep. Anesthesiology 60: 10-18. [Crossref]

3. Moller RA and Covino BG. (1990) Cardiac electrophysiologic properties of lidocaine and bupivacaine compared with those of ropivacaine, a new amide local anesthetic. Anesthesiology 72: 322-329. [Crossref]
4. Swerdlow M, Jones R (1970) The duration of action of bupivacaine, prilocaine and lignocaine. Br J Anaesth 42: 335-339. [Crossref]

5. Bromage PR (1970) Gertel M: An evaluation of two new local anaesthetics for major conduction blockade. Can Anaesth Soc J 17: 557-564. [Crossref]

6. Adams HJ, Kronberg GH and Takman B. (1972) Local anesthetic activity and acute toxicity of (+)-2-(N-ethylpropylamino)-2',6'-butyroxylidide, a new long acting local anesthetic. J Pharm Sci 61: 1829-1831. [Crossref]

7. Liu P, Feldman HS, Covino BM, Giasi R and Covino BG. (1982) Acute cardiovascular toxicity of intravenous amide local anesthetics in anesthetized ventilated dog. Anesth Analg 61: 317-322. [Crossref]

8. Tanz RD, Heskett T, Loehning RW, Fairfax CA. (1984) Comparative cardiotoxicity of bupivacaine and lidocaine in the isolated perfused mammalian heart. Anesth Analg 63: 549-556. [Crossref]

9. Mazoit JX, Boico O and Samli K. (1993) Myocardial uptake of bupivacaine. II Pharmacokinetics and pharmacodynamics of bupivacaine enantiomers in the isolated perfused rabbit heart. Anesth Analg 77: 477-482. [Crossref]

10. Morrison SG, Domínguez JJ, Frascarolo P. and Reiz S. (2000) A comparison of the electrocardiographic cardiotoxic effects of racemic bupivacaine, levobupivacaine, and ropivacaine in anesthetized swine. Anesth Analg 90: 1308-1314. [Crossref]

11. Valenzuela C, Delpo'n E, Tamkun MM, Tamargo J and Snyders DJ (1995) Stereoselective block of a human cardiac potassium channel (Kv1.5) by bupivacaine enantiomers. Biophys J 69: 418-427. [Crossref]

12. Berde CB (1993) Toxicity of local anesthetics in infants and children. J Pediatr 122 S14-20. [Crossref]

13. De Negri P, Ivani G, Tirri T, Del Piano AC (2005) New local anesthetics for pediatric anesthesia. Curr Opin Anaesthesiol 18: 289-292. [Crossref]

14. Sun LS and Rosen MR (1991) The electrophysiologic effects of bupivacaine on adult neonatal and fetal guinea pig papillary muscles. Anesthesiology 74: 893-899. [Crossref]

15. Gunter JB (2002) Benefit and risks of local anesthetics in infants and children. Paediat Drugs 4: 649-672. [Crossref]

16. Simon L, Kariya N, Edouard A, Benhamou D and Mazoit JX (2004) Effect of bupivacaine on the isolated rabbit heart: developmental aspect on ventricular conduction and contractility. Anesthesiology 101: 937-944. [Crossref]

17. Kiuchi MG, Zapata-Sudo G, Trachez MM, Ririe D, Sudo RT (2011) The influence of age on bupivacaine cardiotoxicity. Anesth Analg 112: 574-580. [Crossref]

18. Zapata-Sudo G, Trachez MM, Sudo RT and Nelson TE. (2001) Is comparative cardiotoxicity of S (-) and R (+) bupivacaine related to enantiomer-selective inhibition of L-type Ca (2+) channels? Anesth Analg 92: 496-501. [Crossref]

19. Valenzuela C, Snyders DJ, Bennett PB, Tamargo J, Hondeghem LM (1995) Stereoselective block of cardiac sodium channels by bupivacaine in guinea pig ventricular myocytes. Circulation 92: 3014-3024. [Crossref]

20. Olschewski A, Olschewski H, Bräu ME, Hempelmann G, Vogel W, et al. (1999) Effect of bupivacaine on ATP-dependent potassium channels in rat cardiomyocytes. $\mathrm{Br} \mathrm{J}$ Anaesth 82: 435-438. [Crossref]

21. Rossner KL, Freese KJ (1997) Bupivacaine inhibition of L-type calcium current in ventricular cardiomyocytes of hamster. Anesthesiology 87: 926-934. [Crossref]

22. Komai H, Lokuta AJ (1999) Interaction of bupivacaine and tetracaine with the sarcoplasmic reticulum $\mathrm{Ca} 2+$ release channel of skeletal and cardiac muscles. Anesthesiology 90: 835-843. [Crossref]

23. Lynch C 3rd (1986) Depression of myocardial contractility in vitro by bupivacaine, etidocaine, and lidocaine. Anesth Analg 65: 551-559. [Crossref]

24. Chedid NG, Sudo RT, Aguiar MI, Trachez MM, Masuda MO, et al. (2006) Regulation of intracellular calcium by bupivacaine isomers in cardiac myocytes from Wistar rats. Anesth Analg 102: 792-798. [Crossref]

25. Mio Y, Fukuda N, Kusakari Y, Tanifuji Y and Kurihara S. (2002) Bupivacaine attenuates contractility by decreasing sensitivity of myofilaments to $\mathrm{Ca} 2+$ in rat ventricular muscle. Anesthesiology 97: 1168-1177. [Crossref]

26. Dyhre H, Lang M, Wallin R, and Renck H (1997) The duration of action of bupivacaine, levobupivacaine, ropivacaine and pethidine in peripheral nerve block in the rat. Acto Anaesthesiol Scand 41:1346-1352. [Crossref]

27. Oda Y, Ikeda Y (2013) Effect of lipid emulsion on the central nervous system and cardiac toxicity of bupivacaine and levobupivacaine in awake rats. J Anesth 27: 500504. [Crossref] 
28. Lemoine S, Rouet R, Manrique A, and Hanouz JL (2014) Effect of long-chain triglyceride lipid emulsion on bupivacaine-induced changes in electrophysiological parameters of rabbit Purkinje cells. Fundam Clin Pharmacol 28: 481-488. [Crossref]

29. Hori K, Matsuura T, Tsujikawa S, Mori T, Kuno M, et al. (2015) The significant contribution of the partitioning effect in lipid resuscitation for bupivacaine-induced cardiotoxicity: evaluation using centrifuged solution in vivo and in isolated hearts. $\mathrm{BrJ}$ Anaesth 115: 935-937. [Crossref]

30. Escobar AL, Ribeiro-Costa R, Villalba-Galea C, Zoghbi ME, Pérez CG, et al. (2004) Developmental changes of intracellular $\mathrm{Ca}^{2+}$ transients in beating rat hearts. $\mathrm{Am} J$ Physiol 286: H971-H978. [Crossref]

31. Pérez CG, Copello JA, Li Y, Karko KL, Gómez L, et al. (2005) Ryanodine receptor function in newborn rat heart. Am J Physiol Heart Circ Physiol 288: H2527-2540. [Crossref]

32. Vetter R, Studer R, Reinecke H, Kolár F, Ostádalová I, et al. (1995) Reciprocal changes in the postnatal expression of the sarcolemmal $\mathrm{Na}+-\mathrm{Ca}(2+)$-exchanger and SERCA2 in rat heart. J Mol Cell Cardiol 27: 1689-1701. [Crossref]

33. Husse B, Wussling M (1996) Developmental changes of calcium transients and contractility during the cultivation of rat neonatal cardiomyocytes. Mol Cell Biochem 163-164: 13-21. [Crossref]

34. Vornanen M (1996) Contribution of sarcolemmal calcium current to total cellular calcium in postnatally developing rat heart. Cardiovasc Res 32: 400-410. [Crossref]

35. Gorza L, Vettore S, Tessaro A, Sorrentino V, Vitadello M (1997) Regional and agerelated differences in mRNA composition of intracellular $\mathrm{Ca}(2+)$-release channels of rat cardiac myocytes. J Mol Cell Cardiol 29: 1023-1036. [Crossref]

36. Escobar AL, Ribeiro-Costa R, Villalba-Galea C, Zoghbi ME, Pérez CG, et al. (2004) Developmental changes of intracellular $\mathrm{Ca} 2+$ transients in beating rat hearts. $\mathrm{Am} \mathrm{J}$ Physiol Heart Circ Physiol 286: H971-978. [Crossref]

37. MacLennan DH, Toyofuku T, Kimura Y (1997) Sites of regulatory interaction between calcium ATPases and phospholamban. Basic Res Cardiol 92 Suppl 1: 11-15. [Crossref]

Copyright: (2017 Kiuchi MG. This is an open-access article distributed under the terms of the Creative Commons Attribution License, which permits unrestricted use, distribution, and reproduction in any medium, provided the original author and source are credited. 